\title{
BABEL POÉTICA \\ A POESIA NA ERA LULA
}

\section{Ademir Demarchi}

ABSTRACT

Reflexão, pelo editor da revista Babel Poética, sobre a poesia brasileira contemporânea e a experiência de edição de um mapeamento dessa poesia sob o tema "Poesia na Era Lula". Circunscrita ao período de 2000 a 2010, a pesquisa e edição foram elaboradas através de edital de patrocínio organizado pelo Ministério da Cultura do Brasil e publicadas em seis edições da revista Babel Poética, distribuída nacionalmente com 10 mil exemplares cada edição.

PalavraS-CHAVE: Poesia brasileira. Contemporâneo. Periódicos. Babel Poética. Revista Babel.
This short essay contents some reflections and critics about Brazilian contemporary poetry which are the result from the experience of mapping and researching the range of poetic production between 2000 and 2010, the so-called "Poetry on Lula Age", by the Editor of Babel Poética magazine.

KEYwords: Brazilian Poetry. Contemporary. Periodicals. Babel Poetics. Babel Magazine.

Ademir Demarchi é escritor, doutor em Literatura Brasileira pela Universidade de São Paulo (USP), editor das revistas BABEL - Revista de poesia, traducão e crítica, Babel Poética, e do selo editorial Sereia Ca(n)tadora. Publicou, entre outros, os livros de poemas Os mortos na sala de jantar (Realejo, 2007) e Pirão de Sereia (poesia reunida, Realejo, 2012). 
BABEL POÉTICA

A POESIA NA ERA LULA

\section{Ademir Demarchi}

\section{BABEL: TODAS AS POÉTICAS}

BABEL - Revista de poesia, tradução e crítica foi criada em 2000 por mim e mais três co-editores, os poetas Mauro Faccioni Filho e Marco Aurélio Cremasco e a crítica de literatura Susana Scramim. Com base em Santos-SP, com os co-editores residindo em Florianópolis-SC e Campinas-SP, a revista, além de circular nesses lugares, teve foco e distribuição nacional entre escritores e instituições, atingindo boa repercussão, comprovada nas colaborações obtidas e em divulgação em outras mídias (como indicações nos cadernos Mais! e Ilustrada da Folha de S. Paulo, no Estadão, no Jornal da Tarde, no caderno Ideias do Jornal do Brasil etc.).

A capa da primeira edição, com um trem em ruínas sugerindo no editorial ser "um motor morto" que se decompunha como símbolo do progresso do século $X X^{1}$, mais os nomes de Milton Hatoum, Boris Schnaiderman, Langston Hughes e Jeffrey McDaniel, correspondendo em conteúdos originais, levou à indicação no caderno Ilustrada da Folha de S. Paulo em reportagem intitulada "Revistas constroem berço da nova poesia"², e também no caderno Mais!, como dica cultural da semana, e provocou uma busca por exemplares por parte de distribuidores, levando a revista graciosamente, num momento em que isso ainda era possível, para a vitrine da Livraria Cultura, já então o metro quadrado mais caro de exposição de livros do país.

Uma visita ao distribuidor logo colocaria esse sucesso no seu devido lugar: sentado em meio a centenas de livros de poesia, ele foi bem duro, dizendo que não nos empolgássemos, pois aquilo era episódico, somente possibilitado pela

\footnotetext{
${ }^{1}$ No ensaio "BABEL - Vista dos anacronismos da revista", Luísa Cristina dos Santos Fontes faz uma análise da revista, apontando sua vocação para a leitura anacrônica. In: Boletim de Pesquisa NELIC, Florianópolis, v. 8, n. 8/9, p. 81-92, 2008.

2 Ilustrada, Folha de S. Paulo, São Paulo, p. E-10, 1 jun. 2000.
} 
indicação conseguida na mídia, que poesia não vendia e muito menos ainda revista de poesia... Devidamente avisados e já prevendo que a possibilidade de um acerto seria remota, fizemos um escambo e levamos o valor das revistas em livros de poesia publicados pela editora 7 Letras... ${ }^{3}$

Não esperávamos a repercussão inicial, mas já sabíamos que poesia e revistas de poesia não vendiam, tanto que todas as edições, das seis realizadas em formato livro com tiragens médias de 500 exemplares, foram feitas sem depender de recursos de venda, bancadas pelos editores e distribuídas de forma dirigida para uma lista de cerca de 200 escritores, críticos e jornalistas.

A revista tinha por objetivos publicar poemas de novos e de reconhecidos autores, entrevistas, críticas, resenhas, traduções. Destacaram-se nessa fase uma enquete sobre cânone, entrevistas minuciosas ou dossiês com Milton Hatoum, Bóris Schnaiderman, Glauco Mattoso, Raúl Antelo, Paulo Franchetti, muitas traduções de várias línguas, entre tantos outros textos.

A experiência durou seis edições, até 2004, sem ter conseguido uma regularidade, inicialmente pretendida que fosse quadrimestral, logo semestral e, ao fim, anual, mas cumpriu os objetivos propostos, procurando ser fiel ao título em sua variedade e não ficando restrita a um grupo. No entanto perdeu seu ímpeto grupal e encerrou-se essa fase na sexta edição, deixando a insatisfação com o modelo, que repetia os formatos das revistas de poesia em geral, ficando também o desejo de se fazer uma leitura mais livre de enquadramentos e performática da poesia contemporânea.

\section{A FALÁCIA DA LEI DE FOMENTO}

Após o encerramento dessa primeira fase da revista, obtive a aprovação de dois projetos no Ministério da Cultura (MinC), através da Lei Rouanet, entre 2005 e 2006, para fins de captação de recursos visando uma série de edições da revista. Concluir a maratona de elaboração do projeto e obter sua aprovação nada significou além de acréscimo à experiência pessoal, uma vez que a

\footnotetext{
${ }^{3}$ Outros aspectos da publicação de revistas como "fantasmagorias", "zonas autônomas de atuação temporária" e distribuição num "mercado fantasmagórico", com relatos dessas experiências, podem ser encontrados no meu ensaio "Literatura e editoração: o perfil das revistas literárias na atualidade", apresentado no II Congresso Nacional de Linguagens e Interação (II CONALI), realizado na Universidade Estadual de Maringá em 2008. In: SILVA, Marciano Lopes e. (Org.). Linguagens em interação I. Literatura, história e sociedade. Maringá: Clichetec, 2009.
} 
Lei Rouanet comprovou-se uma falácia: o governo proclama o investimento em cultura através de uma renúncia fiscal que não se cumpre, uma vez que delega aos empresários o poder de decisão de usar essa renúncia. Ocorre que o empresariado, além de massivamente ignorante e inculto, com um imenso contingente habitando confortavelmente os índices do analfabetismo funcional, não tem interesse em cultura e os que têm algum interesse não o têm em revistas... Ainda mais de poesia, constatei, fazendo um périplo por grandes empresas com setor de marketing focado na cultura (como Cosipa), bancos (como Santander) ou de grande varejo.

\section{A UTÓPICA REDE DE REVISTAS}

Em 2009, sinalizando uma mudança governamental de política para a cultura, através de editais públicos, surgiu então a possibilidade de experimentar um novo formato com um edital do Programa Cultura e Pensamento $2009 / 2010^{4}$ do Ministério da Cultura, que selecionou quatro projetos, dentre os mais de 170 apresentados, para a publicação de revistas com patrocínio da Petrobras, sob coordenação da Associação dos Amigos da Casa de Rui Barbosa $(A A C R B)^{5}$. Após essa definição, a equipe do Programa Cultura e Pensamento decidiu ampliar o número de publicações em mais 16 , objetivando formar um grupo de 20 revistas de vários assuntos que circulariam nacionalmente em Rede constituída para isso, com 6 edições de 10 mil exemplares cada, distribuídos pelo MinC, pelo MEC e outras entidades em universidades, centros culturais, pelas próprias revistas e outros meios diversos.

O projeto da Rede de Revistas foi elaborado por Sergio Cohn através da Associação Cultural de Estudos Contemporâneos (ACEC), em parceria com o Ministério da Cultura, definindo como objetivo "a criação de uma rede alternativa e inovadora de produção e distribuição de periódicos de cultura no Brasil", visando "impulsionar o alcance da produção editorial cultural, crítica e independente, que, justamente, por estas características, enfrentam dificuldade de visibilidade e acessibilidade". ${ }^{6}$

\footnotetext{
${ }^{4}$ BRASIL. Ministério da Cultura. Programa Cultura e Pensamento. Sobre o Programa. 5 ibidem, Revistas contempladas 2009/2010.

${ }^{6}$ Mais informações podem ser obtidas em COHN, Sergio. (Org.). Revistas de invenção. 100 revistas de cultura do modernismo à atualidade. Rio de Janeiro: Beco do Azougue Editorial, 2011, onde há inclusive cópia de publicação no Diário Oficial da União de 3/1/2011 do extrato de convênio da Secretaria de Políticas Culturais do Ministério da Cultura com a ACEC.
} 
Se tivesse sido efetivada, essa seria uma grande novidade na cultura do país, na medida em que se teria um inédito grupo de revistas de vários pontos do país, de assuntos variados, atuando e circulando em 200 pontos de distribuição selecionados. Parecia algo utópico demais, uma bolha de otimismo a mais daquele governo Lula, tal como se pode constatar neste trecho do manifesto veiculado pela Rede de Revistas ao tentar garantir sua continuidade diante do descaso silencioso e demolitório imposto pela ministra Ana de Hollanda:

\begin{abstract}
A Rede de Revistas, mais que um desdobramento do edital, é um projeto a parte, que visa inovar as formas de produção e acessibilidade das revistas de cultura no país. As 20 revistas do projeto constituem uma rede de 245 colaboradores anuentes, distribuídos em 19 estados das cinco regiões do país, e abarcam 15 áreas da cultura contemporânea. É a maior rede de revistas culturais já criada no Brasil, num projeto inovador e de grande mérito cultural, que foi conveniado junto ao Fundo Nacional de Cultura na proposta 084010/2010, com publicação no Diário Oficial da União em 3 de janeiro de $2011 .^{7}$
\end{abstract}

Babel Poética obteve a primeira colocação na seleção, disputando com cerca de 170 outros projetos. O programa se efetivou, afinal, com apenas quatro revistas, Babel Poética, de poesia; Piseagrama, de arte e debate sobre ocupação do espaço público; Recibo, de arte; e Índio, focada nas comunidades indígenas nacionais com temas variados. ${ }^{8}$

A tarefa primordial dessas publicações, feita a discussão entre editores e o grupo gestor, era de dar, com plena liberdade de conteúdo, visibilidade de forma ampla à cultura que se faz no país de modo precário e sem circulação expressiva. Seria uma experiência valiosa também para provar a importância de mecanismos como o do edital, que incentivaria e reforçaria o trabalho dos escritores, artistas e produtores de cultura, ampliando as possibilidades de criação e de acesso à informação num país de numerosos analfabetos reais e funcionais que dão o expressivo número de mais de $75 \%$ de habitantes que não têm hábito de leitura.

\footnotetext{
7 INTERVOZES. Rede de Revistas cobra do governo compromisso com financiamento. Intervozes: coletivo brasil de comunicação social, 12 ago. 2011.

${ }^{8}$ Todas disponíveis online: Piseagrama [piseagrama.org]; Recibo [issuu.com/recibo]; Índio [revistaindio.wordpress.com/edicoes/]; Babel Poética [issuu.com/babelpoetica]. Babel Poética tem também um blogue com outras informações [babelpoetica.wordpress.com/].
} 
Com trâmite demorado, como foi em geral a realização desse Programa de edição das quatro revistas (de 2009 a 2013) o projeto de edição de mais 16 títulos não se concretizou, sendo cancelado na mudança do governo Lula para o governo Dilma, mesmo tendo sido oficializado com a publicação no Diário Oficial e com muita gritaria feita pelos editores para evitar a perda de tempo e energia gastos e dinheiro público investido ${ }^{9}$. O governo Lula teve como ministros da Cultura Gilberto Gil e Juca Ferreira que, em suas atuações, foram abertos ao debate, com constante presença entre os artistas através de audiências públicas, reuniões e consultas públicas com a presença de representantes do MinC, além de grandes incentivadores de projetos e programas criativos e reflexivos como esse das revistas.

A entrada de Dilma no novo governo seguiu caminho contrário na área da cultura, com a ministra Ana de Hollanda, inábil e fechada ao debate e comprovando-se ultraconservadora na medida em que fez retroceder - e ignorar, apagando - todas as discussões ocorridas no governo anterior, levando a efeito ações nocivas para a área, como a do cancelamento de todos os projetos e programas iniciados ou incentivados pelo governo anterior.

Entre tantos desserviços, cancelou-se o projeto de edição das 16 revistas, esfacelou-se a Rede de Revistas organizada trabalhosamente após contatos com cerca de 200 instituições no país para a criação de focos de distribuição das revistas; deixou de se integrar todas essas revistas, até mesmo as quatro publicadas (com 24 edições no total), ao Acervo Digital das Revistas Culturais Brasileiras, da Brasiliana USP, com a qual o MinC estabeleceu parceria para a formação de acervo em seu próprio site; calou-se a possibilidade de trazer à circulação mais ampla a produção cultural criativa que existe de forma underground no país em revistas tão expressivas quanto os assuntos prometidos: Bola (artes visuais); Camarim (teatro); Cinética (cinema); Circo Brasil (circo); Corpografia (dança); Entretrópicos (arquitetura e urbanismo); Etandoné (artes visuais); Fotoativa (fotografia); Matadouro - Revista da Cinemateca Brasileira (cinema); Noz (arquitetura e urbanismo); OBS - Intervozes (cultura digital); Overmundo (cultura digital); Padedê (design); Projétil (produção cultural); Revista de Música (música); Toró (cultura da periferia).

9 INTERVOZES. Rede de Revistas cobra do governo..., op. cit. 
A insatisfação generalizada com aquela ministra levou à sua substituição por Marta Suplicy que, também inexpressiva, após mais de um ano no cargo, serviu apenas para comprovar que o desmonte feito pela ministra anterior era mesmo uma política do governo Dilma.

Apesar do ímpeto demolitório daquela ministra que parecia estar para lá da Holanda, e somente com muita reclamação e esforços contra o descaso do Ministério, os editores das quatro revistas conseguiram sobreviver ao ritmo arrastado iniciado em 2009 com muitos problemas e chegaram à sexta edição de cada uma delas neste ano de 2013.

\section{O EMARANHADO DAS INSTITUIÇÕES}

É interessante observar também a quantidade de instituições envolvidas na execução desse projeto. Isso já se constata pela contracapa de cada revista, onde aparecem os logotipos: Realizadores - Petrobras, Governo Federal, Ministério da Cultura, Secretaria de Políticas Culturais, Associação dos Amigos da Casa Rui Barbosa; Apoio: RNP - Rede Nacional de Ensino e Pesquisa, Ministério da Educação, Rede de Revistas, Programa Cultura e Pensamento, FAPEX; Parceria: Brasiliana USP.

Finalmente, na ponta disso, cada editor teve que buscar uma entidade para estabelecer um convênio de gestão local. No caso da Babel Poética, buscando tornar isso produtivo para além da mera exigência burocrática de gestão administrativa, a revista associou-se com o Centro Camará de Pesquisa e Apoio à Infância e Adolescência, sediado em São Vicente-SP, na Baixada Santista, que é uma entidade focada no trabalho social com jovens em situação de risco. Apesar das inconstâncias de atividade da instituição, foi possível alguma interação com a sua comunidade através de lançamentos da revista e saraus, assim como seus operadores puderam usar amplamente a revista como objeto de trabalho e reflexão com a comunidade envolvida.

\section{A ERA LULA, JÁ ERA?}

A proposta da revista Babel Poética se deu no sentido de fazer um mapeamento da poesia contemporânea no Brasil, circunscrita ao período denominado "Era Lula", ou seja, definido como de 2000 a 2010 aproximadamente, que foi o do governo Lula, dadas as peculiaridades desse momento histórico, 
de remarcado retorno do velho populismo, confirmado na eleição de Lula, e seus desdobramentos consubstanciados em ações de governo, discursos oficiais e, no lado oposto, em discursos reivindicatórios ou de protesto e crítica, muito presentes na poesia desse momento.

A escolha do tema se deveu ao fato de que, nesse período, além da importância histórica de ascensão de um operário ao cargo máximo de poder do país, sob seu governo houve uma combinação que se pode dizer notável e positiva de avanços sociais e econômicos que levou a uma ascensão notória da qualidade de vida em geral, especialmente para grandes contingentes de pessoas situadas na linha da miséria. Empresas apresentaram significativo crescimento, investindo e vendendo mais e exportando como nunca e até mesmo comprando outras empresas fora do país. Trabalhadores conquistaram melhorias salariais e mais empregos, com uma inclusão social e econômica em larga escala de habitantes antes fora do sistema de consumo. Aliado a isso, um conjunto amplo de indicadores no campo da educação, saúde e habitação apresentou evoluções significativas.

$\mathrm{Na}$ área da cultura, ao mesmo tempo, amplificou-se o que o escritor $\mathrm{e}$ crítico Silviano Santiago definiu como "cosmopolitismo do pobre" ${ }^{10}$, em que um grande contingente de pessoas, sobretudo jovens, passou a circular das periferias por todo o país - o Cooperifa, da zona sul de São Paulo, na área de literatura, é um ótimo exemplo - e o fenômeno se deu até mesmo com movimento em direção para fora do país, como foi o caso da Sinfônica de Heliópolis, composta por jovens músicos daquela comunidade que tocaram com o maestro israelense Zubin Mehta e, pela primeira vez, se apresentaram na Sala São Paulo, em despedida para iniciar turnê pela Europa.

Ou seja, se era possível fazer essa interpretação algo positiva do governo Lula, com a entrada de Dilma no governo, sucedendo-o, isso já não foi mais possível, pois não houve uma continuidade das conquistas alcançadas, especialmente na área da cultura, restando, porém, daquele, de forma evidenciada, apenas o discurso e as ações populistas focadas sobretudo nas questões socioeconômicas.

\footnotetext{
${ }^{10}$ Vide SANTIAGO, Silviano. O cosmopolitismo do pobre. In: O cosmopolitismo do pobre. Crítica literária e crítica cultural. Belo Horizonte: UFMG, 2004, p. 45-63.
} 


\section{QUE PAÍS ESTÁ NA POESIA?}

A seleção de poemas respondendo à questão de como veem os poetas o país em que vivem, nesse momento denominado "Era Lula", encontrou um tom negativo, não correspondente àquela descrição já assinalada como algo positiva em relação ao governo Lula.

Pode-se dizer que mais uma vez se viu confirmada, nesse mapeamento, a negatividade característica da poesia: o país que sai dessa poesia, registrada sobretudo na primeira edição, é um lugar de miséria apocalíptica. Não há, aí, perspectiva otimista possível e o eco que ainda se possa encontrar até hoje de um otimismo modernista de progresso é terrível, tal como se comprova no seguinte poema, de Márcio Barreto:

\section{OS ABAPORUS}

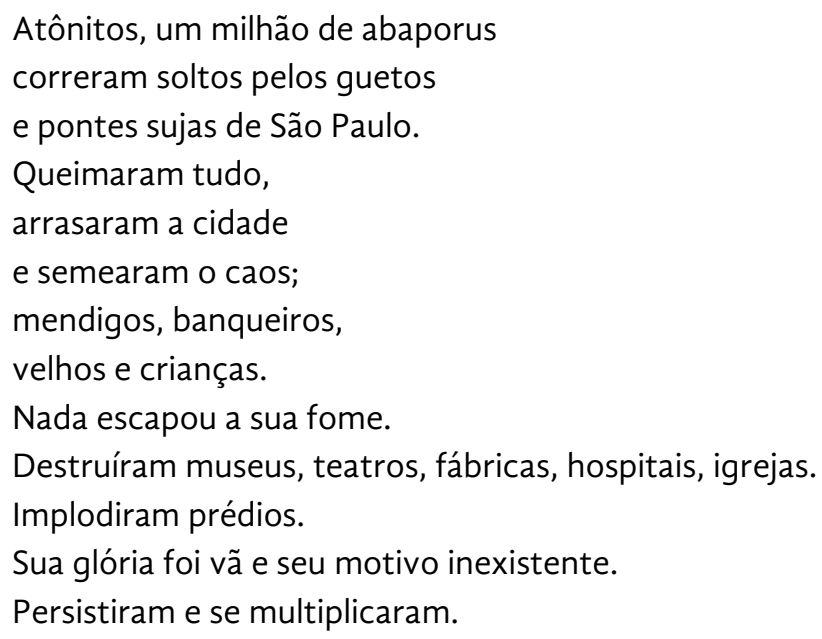

O tom apocalíptico anda de braços dados com o cinismo, tal como no poema Paulo de Toledo, que sugere que o que restou da ideologia de esquerda é a constatação de que a luta de classes, neste país, se dá, verdadeiramente, entre mendigos:

\section{LUTA DE CLASSES}

no chão um cego esmoler imundo

pede uma moeda pro mendigo

e ele: vai trabalhar vagabundo 
A revolta de junho de 2013 que se espalhou pelo país em verdade se arrasta há muito tempo entre a juventude e já estava sugerida em insatisfação nos textos da primeira edição de Babel Poética, de 2010, a começar por textos como os de Marcelo Ariel, de Cubatão, que dá voz aos presidiários e traficantes do PCC em poemas argutos como "Me enterrem com minha AR-15", entremeados de frases como "se tivermos que amar, amaremos; se tivermos que matar, mataremos".

A violência social e urbana rescende dos textos e ecoa ainda a ditadura de 1964, como no poema de Daniel Faria, "Poema brechtiano para um 31 de março esquecido" que afirma que "vencedores e vencidos partilharam o butim", chegando-se à sugestiva síntese do sarcasmo dos poemas de Valério de Oliveira dedicados aos ex-presidentes militares: "Castelo Branco Produtos Alimentícios", "Costa e Silva Publicidade e Propaganda"...

Sebastião Nicomedes, um morador de rua de São Paulo diz que "Quem mora na rua/ não quer voltar pra senzala"; Ricardo Domeneck, morando em Berlim, diz que "O trabalho de um punk tropical/ permanece o de borrar fronteiras,/ aterrar trincheiras", Maicknuclear, um performático urbano, afirma "Eis que me vejo pisando em terras sem lei" e um sem-terra preso, Valquimar Reis Fernandes, cobra "A grade àqueles não a nós."

Da experiência dessa série de edições resta a sensação de que, de tantas, imensas e amuradas instituições dando forma ao poema, chega-se ao descampado absoluto dessa miséria babélica em que a poesia se esvaziou para transformar-se em sintoma. 